\title{
Indigenizando direitos territoriais na utopia modernista: O Santuário dos Pajés e a política de não-reconhecimento dos indígenas em contexto urbano
}

Indigenizing land rights in the modernist utopia: Sanctuary of Pajés and the politics of non-recognition of indigenes in the urban context

\section{Cristhian Teófilo da Silva}

\section{(2) OpenEdition}

\section{Journals}

\section{Edição electrónica}

URL: https://journals.openedition.org/aa/8288

DOI: 10.4000/aa.8288

ISSN: 2357-738X

\section{Editora}

Programa de Pós-Graduação em Antropologia Social (UnB)

\section{Edição impressa}

Paginação: 12-25

ISSN: 0102-4302

\section{Refêrencia eletrónica}

Cristhian Teófilo da Silva, «Indigenizando direitos territoriais na utopia modernista: O Santuário dos Pajés e a política de não-reconhecimento dos indígenas em contexto urbano», Anuário Antropológico [Online], v.46 n.2 | 2021, posto online no dia 30 maio 2021, consultado o 01 junho 2021. URL: http:// journals.openedition.org/aa/8288 ; DOl: https://doi.org/10.4000/aa.8288

\section{(c) $(1) \odot$}

Anuário Antropológico is licensed under a Creative Commons Atribuição-Uso Não-Comercial-Proibição de realização de Obras Derivadas 4.0 International. 


\title{
anuário antropológico \\ v. $46 \cdot \mathrm{n}^{\circ} 2 \cdot \mathrm{majo-agosto} \cdot 2 \odot 21.2$
}

\section{Indigenizando direitos territoriais na utopia modernista: 0 Santuário dos Pajés e a política de não- reconhecimento dos indígenas em contexto urbano ${ }^{1}$}

Indigenizing land rights in the modernist utopia: Sanctuary of Pajés and the politics of nonrecognition of indigenes in the urban context

DOI: https://doi.org/10.4000/aa.8288

\author{
Cristhian Teófilo da Silva \\ Universidade de Brasília, Instituto de Ciências Sociais, Departamento de Estudos Latino- silvacteunb.br \\ -Americanos, Brasília, DF, Brasil \\ Antropólogo., Professor Associado no Departamento de Estudos Latino-Americanos (ELA) da Universidade \\ de Brasília (UnB). Pesquisador Associado no CIÉRA (ULaval) e Bolsista PQ-2 do CNPq. Fundador e coordena- \\ dor do LAEPI e do OBIND.
}

Este trabalho trata dos efeitos das classificações oficiais sobre identidades, pessoas e corpos indígenas em contextos urbanos, com ênfase para a resistência da comunidade multiétnica do Santuário dos Pajés em Brasília, Distrito Federal. O objetivo é refletir sobre as possibilidades de re-existência indígena no âmbito da tríade Estado, violências e regulações. Parte-se dos conceitos de indigenismo, biopoder e práticas do poder tutelar para situar questões relativas à indianidade e estadania dos indígenas em contextos urbanos via de regra excluídos da assistência indigenista. Trata-se de pensar as violências e obstáculos à cidadania daqueles que são culturalmente definidos como "Outros" ou "diferentes" pela sociedade dominante, em particular em situações de reivindicação de áreas de ocupação tradicional indígena nas cidades.
This work deals with the effects of official classifications on indigenous identities, people, and bodies in urban contexts, with emphasis on the resistance of the multi-ethnic community of the Sanctuary of Pajés in Brasilia, Federal District of Brazil. The objective is to reflect on the possibilities of indigenous re-existence within the scope of the triad State-violence-regulations. It starts with the concepts of indigenism, biopower, and practices of the tutelary power to situate issues related to the indigeneity and stateship of Indigenous Peoples in urban contexts as they are excluded from ethnic policies. It is a question of thinking about the violence and obstacles to citizenship of those who are culturally defined as "Others" or "different" by the dominant society, particularly in situations of areas claimed as traditional indigenous lands in cities. 


\section{Introdução}

Este trabalho trata dos efeitos das classificações oficiais sobre identidades, pessoas e corpos indígenas em contextos urbanos, assim como da violação dos direitos humanos destes povos e pessoas indígenas decorrentes do racismo institucional inerente à prática tutelar do indigenismo brasileiro, de ontem e de hoje. Este conceito, de racismo institucional (Carmichael; Hamilton, 1967; Williams, 1985), se mostra muito útil, sobretudo quando conjugado às práticas e políticas de não-reconhecimento (MILLER, 2003), para elucidar e explicar os baixos níveis de qualidade de vida e a consequente migração das reservas e terras indígenas de indivíduos e famílias indígenas que passam a viver em cidades.

O objetivo é refletir sobre as possibilidades de re-existência indígena, i.e., de existir de novo, de existir ainda, no âmbito da tríade Estado, violências e regulações. Desse modo, a ideia é partir de conceitos de indigenismo, biopoder e práticas do poder tutelar para situar questões relativas à indianidade e estadania dos indígenas em contextos urbanos via de regra excluídos pela assistência indigenista.

\section{Regimes de indianidade como regulações estatais}

O que se segue é uma aproximação, bastante preliminar ainda, para contribuir com o diagnóstico das violências sofridas e os principais empecilhos à plena cidadania daqueles sujeitos cujos corpos são invisibilizados pelos regimes de regulação da identidade étnica de povos indígenas no Brasil.

Trata-se de pensar as violências e obstáculos à cidadania daqueles que são culturalmente definidos como "Outros" ou "diferentes" pela sociedade dominante. Este objetivo coincide diretamente com um dos problemas de pesquisa que venho trabalhando em minhas últimas pesquisas etnográficas (Teófilo da Silva, 2002; Teófilo da Silva, 2010) junto aos povos Tapuio e Avá-Canoeiro, respectivamente, qual seja compreender como se constituem, a partir dos Estados, os regimes de regulação das identidades, das culturas e dos territórios dos povos indígenas com vistas à sua inserção/assimilação/integração nas sociedade nacionais ditas modernas, com especial ênfase para os povos ou pessoas que não se enquadram, necessariamente, na definição jurídica de "indígena”, mas assim se autodeclaram.

A estes regimes de regulação criados e mantidos pelos agentes estatais para classificar os indígenas como seus objetos de ação eu denomino "regimes de indianidade". E a negação ou recusa administrativa de lidar com a identidade étnica de pessoas e coletividades que se autoidentificam como povos indígenas, recusando-lhe, por conseguinte, os direitos, serviços e recursos que lhes seriam previstos, denomino, apoiado em Miller (2003), "políticas de não-reconhecimento".

Os "regimes de indianidade" resultam historicamente das ideologias indigenistas próprias de cada país que adota discursos e práticas, ora de integração ora de reconhecimento, das populações colonizadas, através de normas, regulamentações, leis, políticas etc., com o objetivo de criar e manter a ideia de um Estado
1 Trabalho apresentado na Mesa 1: "Territórios e Conflitos Socioambientais", realizada no âmbito do Seminário "Territórios, Cidades e Migrações - Diálogos Interdisciplinares", INCT - Brasil Plural (IBP), Florianópolis - SC, de 12 a 13 de setembro de 2019. 
nacional moderno e coeso. Dito de outro modo, os regimes de indianidade referem-se a paradigmas administrativos de gestão da diversidade indígena.

Estes paradigmas são formados por valores, objetivos, ideias, ideais, classificações, legislações, ações, programas, práticas, orçamentos e instituições próprias, em suma, por formas específicas de regulação das pessoas, sociedades e vidas indígenas, de modo a adequar sua diversidade a uma ideia de Estado nacional que tanto pode se apresentar idealmente como unitário e homogêneo (Bonfil Battalla, 2006, chamava-o "Estado imaginário"), como plural e multicultural, a depender da época e do lugar.

O que esta noção pretende ressaltar, porém, é a violação da autonomia e da liberdade indígenas como fundamento para seu governo nas sociedades modernas. A violência estatal é antes constitutiva do que um efeito dos regimes de indianidade, sejam estes assimilacionistas ou multiculturalistas. Isto significa dizer que a práxis indigenista exercida sobre corpos, identidades e culturas indígenas é uma violência em si mesma geradora de outras violências porque ela parte do princípio que os indígenas devem ser incorporados a nossas ideologias nacionais que, via de regra, não levam em conta suas visões de mundo, modos de vida e, principalmente, processos e dramas sociais. Para falar mais diretamente, trata-se de colonialismo como experiência vivida cotidianamente e não como conceito histórico (Taiaiake Alfred, 2009).

Nestes regimes, a tutela indigenista desponta como forma de gestão da diversidade. Não só no Brasil, como em outros países, a exemplo do Canadá, a tutela é acionada como forma de proteção paternalista dos povos indígenas e dos direitos atribuídos a estes, o que não deixa de ser um paradoxo porque nos leva à falsa crença de que o Estado cuida dos indígenas quando, na verdade, atua como um dos seus principais agressores, pois a tutela não é uma opção ou resultado de uma colaboração, mas uma imposição.

Pensar a tutela indigenista como uma forma de violência, ou melhor, uma prática cotidiana da dominação interétnica a que os indígenas estão submetidos, pode ser tornado mais evidente ao nos utilizarmos do conceito de biopoder tal como definido por Michel Foucault, ao tratar da governamentalidade (1995 [1979]). Este não é o lugar nem o momento para discorrermos sobre o conceito de biopoder em seu sentido original foucaultiano. Por ora, cabe apenas pensá-lo e utilizá-lo como a biopolítica em ação, isto é, quando o poder se transforma em técnica de governo fazendo da população e do território objetos, e o controle e disciplinarização desses objetos sua razão de ser.

No Brasil, foi Antonio Carlos de Souza Lima quem primeiro realizou a apropriação conceitual do biopoder, tal como definido por Foucault, para interpretar o indigenismo de Estado. Para isso, elaborou o conceito de poder tutelar a fim de analisar as ideias, ideais e práticas levadas a cabo pelo Serviço de Proteção aos Índios e Localização de Trabalhadores Nacionais (SPILTN), depois SPI, e que foi sucedido somente em 1967 pela Fundação Nacional do Índio (FUNAI). Sirvo-me do resumo do conceito feito por Marcos Otávio Bezerra para acessarmos mais rapidamente a importância da apropriação feita por Souza Lima: 
Trata-se de um poder estatizado, exercido sobre populações e territórios, que busca assegurar o monopólio dos procedimentos de definição e controle sobre as populações indígenas. Para tanto, são meios importantes e ao mesmo tempo seus produtos, a formulação de um código jurídico acerca das populações indígenas e a implantação de uma malha administrativa instituidora de um governo dos índios. O exercício do "poder tutelar" sobre os índios possui características específicas que não devem ser confundidas com outras formas de poder dirigidas a essas populações. 0 "poder tutelar" é concebido como uma forma reelaborada - com continuidades lógicas e históricas - da "guerra de conquista". Enquanto modelo analítico, define o autor, a "conquista" é um empreendimento com distintas dimensões: fixação dos conquistadores nas terras conquistadas, redefinição das unidades sociais conquistadas, promoção de fissões e alianças no âmbito das populações conquistadas, objetivos econômicos e empresa cognitiva (Bezerra, 1997, n. p.).

Dito isso, o aspecto central a ser retido consiste em reconhecer como do

ponto de partida do exercício do poder tutelar e ao mesmo tempo seu produto, as classificações elaboradas pelo Serviço acerca dos índios (e que) estão na origem de suas ações. Concebidos pelo órgão como seres em transição, suas ações estavam voltadas para proporcionar a incorporação dos índios à categoria de trabalhadores agrícolas (idem, n. p., negritos e parêntesis adicionados).

Uma vez que apreendemos a centralidade das classificações indigenistas para o exercício do poder tutelar na qualidade de um "governo dos índios" segundo regimes de indianidade específicos, começamos a reconhecer a qualidade profunda e extensa (por que não dizer, totalitária?) da dominação experimentada pelos indígenas no Brasil. Trata-se de uma dominação que começa por negar e mesmo impedir que os povos indígenas participem do poder de definição e representação pública de suas próprias identidades e corpos, e isto se dá sob regimes que anunciam uma preocupação ambígua com a proteção dos indígenas.

Nesse sentido, vejamos o que diz textualmente o Estatuto do Índio (Lei 6.001 de 1973), ainda em vigor, que segue sendo responsável pela regulação das identidades indígenas no âmbito Estatal:

Art. 1. Esta Lei regula a situação jurídica dos índios ou silvícolas e das comunidades indígenas, com o propósito de preservar a sua cultura e integrá-los, progressiva e harmonicamente, à comunhão nacional.

Parágrafo único. Aos índios e às comunidades indígenas se estende a proteção das leis do País, nos mesmos termos em que se aplicam aos demais brasileiros, resguardados os usos, costumes e tradições indígenas, bem 
como as condições peculiares reconhecidas nesta Lei (Lei 6.001, art. 1º).

$\mathrm{O}$ artigo traz em poucas linhas um denso conjunto de preconceitos, muitos de origem colonial, contra os indígenas, como o de serem "habitantes das florestas", vivendo em "condições peculiares" e "transitórias" que são tornadas objetos do biopoder tutelar até o seu completo desaparecimento, eufemisticamente chamado de "integração progressiva e harmoniosa à comunhão nacional". Evoca, assim, um processo antropofágico de construção da nação.

A contradição inerente ao texto legal alega o propósito de preservar as culturas indígenas, ao mesmo tempo em que intenciona integrar seus membros à sociedade nacional. Isto enseja, na verdade, não uma contradição, mas um dilema: ou se preservam as culturas mantendo-se os indígenas fora da nação (trata-se de uma "exceção na inclusão", o que é diferente de uma simples exclusão, diria Giorgio Agamben (2004) [1995]) ou se promove sua "integração progressiva" destruindo suas culturas, o que nunca será alcançado de forma harmoniosa, pois trata-se simplesmente de etnocídio, quando não de genocídio (ver Teófilo da Silva, 2010, p. 103-104). Este dilema, na verdade, não é um dilema indígena, mas um dilema inventado para equacionar uma não menos inventada "questão indígena” que justifica todo o edifício indigenista erguido - já em estado de abandono - para paternalisticamente administrá-los e a seus territórios.

As classificações indigenistas desempenham aí um papel fundamental para emular este falso dilema como realidade autoevidente, ao fazer da transitoriedade do "índio" algo intrínseco à sua natureza (as chamadas "condições peculiares"), o que faz da integração sociocultural um processo inexorável. Portanto, são as definições de "índio", tais como expressas nos Artigos $3^{\circ}$ e $4^{\circ}$ da Lei, as que merecem maior atenção neste momento, especialmente, se quisermos analisar como o poder tutelar, na qualidade de "proteção paternalista e fraternal", é acionado contra os indígenas e a favor dos interesses e representações que a sociedade dominante faz deles:

Art. $3^{\circ}$ Para os efeitos de lei, ficam estabelecidas as definições a seguir discriminadas:

I - Índio ou Silvícola - É todo indivíduo de origem e ascendência pré-colombiana que se identifica e é identificado como pertencente a um grupo étnico cujas características culturais o distinguem da sociedade nacional;

II - Comunidade Indígena ou Grupo Tribal - É um conjunto de famílias ou comunidades índias, quer vivendo em estado de completo isolamento em relação aos outros setores da comunhão nacional, quer em contatos intermitentes ou permanentes, sem contudo estarem neles integrados.

Art. $4^{\circ}$ Os índios são considerados: 
I - Isolados - Quando vivem em grupos desconhecidos ou de que se possuem poucos e vagos informes através de contatos eventuais com elementos da comunhão nacional;

II - Em vias de integração - Quando, em contato intermitente ou permanente com grupos estranhos, conservam menor ou maior parte das condições de sua vida nativa, mas aceitam algumas práticas e modos de existência comuns aos demais setores da comunhão nacional, da qual vão necessitando cada vez mais para o próprio sustento;

III - Integrados - Quando incorporados à comunhão nacional e reconhecidos no pleno exercício dos direitos civis, ainda que conservem usos, costumes e tradições característicos da sua cultura.

Seria quase desnecessário dizer que todas estas definições perderam respaldo com a promulgação do Art. 231 da Constituição Federal de 1988, seguido do Art. 232, da ratificação da Convenção n ${ }^{\circ}$ 169/89 da Organização Internacional do Trabalho (OIT) em 2004 e diante da Declaração das Nações Unidas sobre os Direitos dos Povos Indígenas de 2007. Entretanto, as mudanças não se passam tão rapidamente como poderiam, sobretudo quando não há investimentos sinceros em reformas institucionais dos órgãos do Estado, suas políticas e práticas administrativas, para se adequarem às novas diretrizes e concepções.

Nesse sentido, a orientação tutelar e assimilacionista segue sendo sistematicamente acionada pelo sistema de justiça brasileiro em situações nas quais os indígenas aparecem como réus ou vítimas em processos criminais (Menezes, 2019), assim como segue informando e orientando processos administrativos relacionados às políticas de proteção social, à operacionalização dos direitos das crianças e adolescentes, às políticas de desenvolvimento, educação, saúde etc., e também está presente nos novos projetos de lei (à exceção do novo Estatuto do Índio que tramita há mais de 30 anos no Congresso), de emenda à constituição, decretos legislativos etc., independentemente, insisto, de toda normativa em contrário, tanto infraconstitucional e constitucional, quanto internacionalmente. Tudo isto denota a perenidade do regime de indianidade integracionista, bem como sua resiliência mesmo em ambientes declaradamente multiculturais ou etnicamente plurais.

Ou seja, em todas as dimensões cotidianas da vida dos indígenas no Brasil, as definições legais operam como formas de classificação de sua condição perante a sociedade nacional para fins de regulação do acesso a direitos fundamentais, políticas sociais e políticas indigenistas tendo por base que os mesmos estão em processo de "desindianização" ou, para falar na linguagem ainda corrente de boa parte dos operadores do direito e das políticas públicas no país, em processo de "aculturação". E, uma vez aculturados, não seriam mais dignos de políticas de proteção específicas.

Esta é, precisamente, a base da política de não-reconhecimento, pois, quanto mais os indígenas são classificados como "integrados" mais abandonados são pe- 
los agentes estatais. Isto se manifesta como uma "jaula de ferro" - para empregar a terminologia weberiana sobre a administração burocrática racional - para os indígenas que se veem obrigados a viver e expressar, na maioria das vezes de modo público, ou melhor "exótico" até para eles mesmos, sua indianidade, em acordo com os termos prescritos para eles pelo imaginário preconceituoso das sociedades modernas. As situações sociais em que isto se torna mais evidente são justamente aquelas propiciadas pela política interétnica, no movimento indígena, nas marchas, protestos, dentre outras formas de luta acionadas pelos indígenas para retomar o poder de definição e representação de seus territórios, identidades, corpos e sexualidades, o que vem a ocorrer, principalmente, nas cidades e capitais políticas ou administrativas.

Nesse sentido, gostaria de apresentar um caso, dos inúmeros casos possíveis, que considero bastante elucidativo do que está sendo argumentado até aqui. $\mathrm{O}$ caso está situado na cidade de Brasília, Distrito Federal, e ficou conhecido como Santuário dos Pajés.

\section{A resistência indígena na cena urbana do Distrito Federal}

O Santuário dos Pajés, como ficou conhecida a área reivindicada por indígenas de diferentes etnias (Fulni-ô, Xucuru, Kariri-Xocó, Nambiquara, Tuxá e Guajajara) que se aldearam na capital federal, constitui, ao meu ver, uma situação exemplar do tipo de drama interétnico que o indigenismo brasileiro engendra para as pessoas e povos indígenas através do atual regime de indianidade e as políticas de não-reconhecimento que ele tem viabilizado.

Vou utilizar, de maneira resumida, o trabalho realizado pelo antropólogo Christian Crevels, quem abordou diretamente o conflito, ou melhor, as disputas de definição da situação de conflito, como objeto de sua etnografia. Segundo seu relato,

durante o governo de José Roberto Arruda (2007-2010), marca-se a votação do novo Plano Diretor para Brasília, que irá gerir diretamente a construção e concepção de um novo bairro no Plano Piloto, o Setor Noroeste. 0 bairro já vinha sendo anunciado em jornais e reportagens de televisão há anos, mas até então não saía do papel (Schvarsberg, 2009).

O grupo de indígenas (Fulniôs, Tuxás, Kariri-Xocós, Wapishana, dentre outros) residente no Santuário dos Pajés (antiga fazenda Bananal com cerca de 50 hectares), preocupado com a integridade de seu território (ocupado desde o final dos anos 1960, quando da migração indígena para a capital em construção) e a invisibilidade que sentiam junto aos órgãos nos quais buscavam por ajuda, decide pedir apoio à população para se manifestarem contra o implemento do novo bairro.

Sob a liderança do pajé Santxiê (também chamado de Santxiê Tapuia, de origem Fulniô e servidor da Funai em Brasília, falecido em 2014), começa a se formar um grupo de apoiadores da resistência dos indígenas junto 
a seus contatos da sociedade brasiliense, que atua conjuntamente com estes e sob o pedido e a supervisão dos próprios indígenas. Os primeiros apoiadores e apoiadoras, que por uma ou outra razão já possuíam relações com os indígenas, divulgam a situação pelas mídias sociais, fazendo o gérmen do movimento de apoio com a chegada de mais pessoas dispostas a ajudar. Ainda não completo em sua visibilidade, tamanho e potencialidade política, o movimento a partir daqui passa a tomar suas primeiras formas. É nesse contexto que o mote "santuário não se move" surge e começa a se difundir (...) A mobilização, embora crescente, não consegue alterar o cenário político e o projeto invariavelmente passa, no entanto, o movimento consegue chamar a atenção de inúmeras pessoas que se aliam à causa, e também da FUNAl, que abre novo processo de estudo do local. Durante 2009, alguns embates se seguem entre os manifestantes e o Governo Distrital, representado então pela TERRACAP - Companhia Imobiliária de Brasília - e as primeiras invasões de território são paradas pelos apoiadores: são tentativas de início das obras de infraestrutura realizadas pelo órgão responsável pela gestão das terras do Distrito Federal. Longos caminhos entre os hectares do Santuário são abertos em desmatamento, mas as obras não se concluem devido às constantes manifestações. Consta que o Ministério Público foi alertado que tratores de empresa licenciada pela TERRACAP adentram o local, na data específica de 27 de outubro de 2009.

Correm em separado ações jurídicas expedidas pelos advogados aliados à causa do Santuário dos Pajés e os autos dos processos de número 08620.000.207/09 e 08620.002418/07, referentes à questão, se enchem de pedidos e protocolos do Ministério Público, preocupado com as possíveis transgressões aos direitos humanos e indígenas que parecem decorrer do empreendimento de construção do bairro. Apontam, eminentemente, a omissão da FUNAI em resolver sobre a tradicionalidade da área ou fazer-se presente na resolução do conflito.

De fato, durante os embates na área e as manifestações realizadas, nota-se estranhamente a falta de representantes da FUNAI para intermediar a situação ou mesmo apenas mostrarem-se cientes da demanda indígena. Isso não quer dizer que a Fundação restou inerte e inativa sobre o caso do Santuário, (...) mas é significativo que não demonstra interesse inicialmente em tomar a questão para si e envolver-se intimamente com ela ou com seus atores, fosse para ajudá-los ou apenas aconselhá-los frente a tão complexo imbróglio. Ou pior, demonstra deliberado desinteresse.

Durante o ano de 2010 e o início de 2011 o Santuário dos Pajés vive um breve período de calmaria, vez que o Plano Diretor conseguiu ser aprovado. Subsiste, no entanto, o sentimento de apreensão, vez que não se sabe exatamente onde o bairro será construído e como será a decisão da FUNAl e 
do Ministério Público sobre o território dos indígenas. $\mathrm{O}$ antropólogo Jorge Eremites coordena uma investigação de campo para fornecer um laudo inicial, segundo pedido da FUNAI. Em seu relatório, ele ressalta a necessidade de abertura do Grupo de Trabalho para a demarcação das terras, pontuando que considera a ocupação como tradicional e merecedora da homologação. No entanto, seu parecer é ignorado e a autarquia não instaura o processo, afirmando por algum tempo que este não lhe chegou em mãos, ao que o Ministério Público aplica multa diária ao órgão e a Jorge Eremites. Então o próprio antropólogo se vê na posição de divulgar virtualmente seu laudo para desmentir isso. 0 bairro começa a ser erigido ao redor do Santuário dos Pajés, tornando-se realidade na paisagem dos indígenas.

Em agosto do ano 2011, a TERRACAP recomeçou obras de infraestrutura na área, alarmando os Fulni-ô. Já no dia 3 de Outubro, o primeiro local dentro dos 50 hectares reivindicados pelo Santuário foi adentrado pela Emplavi Incorporações Imobiliárias LTDA, gerando protestos e manifestações por parte do grupo de apoio aos indígenas. Nas semanas seguintes, juntaram-se a ela mais duas construtoras, Brasal Incorporações e Construções de Imóveis LTDA e João Fortes Engenharia S/A, adentrando a área e desmatando o cerrado para iniciar a construção dos condomínios das Superquadras SQNW 108 e 107.

Ao longo do período, a FUNAl absteve-se em continuar o processo de demarcação da área pelo GT de identificação e delimitação, alegando que não a considera como território de ocupação tradicional (Informação Técnica n 67/ CGID/2011), apesar do laudo feito para o órgão por Jorge Eremites e os pareceres e relatórios de Rodrigo Nacif, Stella da Matta Machado e Marcos Paulo Fróes Schettino afirmarem o contrário. Por meio do seu procurador-geral, Antônio Salmeirão, a instituição nega o relatório que ela mesma encomendou. "Aquela não é uma área tradicionalmente ocupada. Esse é o entendimento da FUNAl", disse (reportagem por Tadeu Breda, 13 de outubro de 2011) (idem, p. 25-26). (Crevels, 2017, p. 23-24, parêntesis adicionados).

Como se pode notar neste caso, a presença multiétnica indígena em uma área de 50 hectares na Capital Federal desde o final dos anos 1960, período que coincide com o fim das obras de construção da capital federal, foi objeto de uma política de não-reconhecimento por parte do órgão indigenista com sede na capital apesar do parecer favorável de especialistas, do Ministério Público Federal (MPF) e da própria justiça do DF e territórios. A FUNAI negou sistematicamente a inclusão da reivindicação indígena na cidade de Brasília no rol das áreas para serem identificadas segundo os atuais procedimentos de regularização fundiária estabelecidos como principal política indigenista brasileira.

A descaracterização da legitimidade da reivindicação indígena do Santuário dos Pajés como terra de ocupação tradicional exemplifica de que modo o estabelecimento do território precede e prescreve o status legal dos indígenas que nele 
vivem, regulando, por conseguinte, as possibilidades de acesso ou não a direitos, serviços públicos e cidadania. Para o caso em questão, entende-se que do ponto de vista do órgão indigenista, classificar o Santuário dos Pajés como Terra Indígena significaria necessariamente reconhecer a aldeia multiétnica indígena como um novo "povo indígena", o que deflagraria uma nova fase de políticas de reconhecimento e demandas por terras, serviços e recursos, agora em contextos urbanos, tendo o caso do Santuário como precedente.

Como já observou o antropólogo Bruce Miller a propósito das políticas de não-reconhecimento, trata-se de uma negociação pública da indianidade de grupos e pessoas indígenas com o propósito burocrático de evitar novas despesas e gastos no já minguado orçamento da administração indigenista. Nesse sentido, é importante dizer que, segundo dados do Censo Demográfico de 2010 e recente estudo da Companhia de Planejamento do Distrito Federal (CODEPLAN) de 2015, residem no DF 6.128 indígenas, em sua maioria concentrados nas partes urbanas das cidades de Ceilândia e Cidade Ocidental, porém "invisibilizados" pelo atual regime de indianidade que repercute sobre a própria academia, que tampouco os enxerga e, por isso, os silencia. Este dado, somado à constatação de uma crescente presença indígena nas cidades em um processo multifacetado que ainda carece de estudos mais aprofundados, constitui uma preocupação óbvia para o órgão indigenista de lidar com reivindicações por terras por parte de "índios urbanos", um eufemismo para "integrados", como têm sido chamados.

Para além de uma mera racionalidade econômica de contenção de despesas, o que se revela com o atual regime de indianidade é o esforço permanente do órgão indigenista de conter a diversidade étnica indígena no âmbito de unidades territoriais tradicionais, justamente aquelas mais afeitas à operacionalização do novo paradigma multiculturalista que tem se mostrado conveniente para a neoliberalização das políticas indigenistas. Entretanto, este esforço de contenção esbarra nas dinâmicas mais complexas e variáveis dos processos reais de formação de alteridades indígenas no país, protagonizadas pelos próprios indígenas em sua política, movimentos e diásporas.

\section{Conclusão: o não-reconhecimento como biopoder indigenista}

Neste ponto, podemos voltar à discussão inicialmente proposta, lembrando que se não bastasse o Estatuto do Índio regular de maneira totalizante as identidades indígenas, estas classificações, após a constituição de 1988, são ainda operacionalizadas pelos três poderes e nas três esferas administrativas (municipal, estadual e federal) a partir da localidade de moradia do indígena, se dentro ou fora, de terras ou reservas indígenas reconhecidas pelo Estado.

Dito de outro modo, para ser "índio" no Brasil, não basta nascer indígena, pertencer a uma família e a um povo que assim se autodetermina e o reconhece como membro, o que está previsto na Constituição Federal, na Convenção 169/ OIT e na Declaração das Nações Unidas sobre os Direitos dos Povos Indígenas. Faz-se necessário ser classificado como tal a partir do Estado através de uma "po- 
lítica de reconhecimento" que no Brasil se dá de modo discricionário e informal pelos agentes públicos detentores do poder de enquadrar os indígenas em um dos três estágios que os levarão, desde o nascimento, à integração com a sociedade nacional. É isto que significa dizer que os indígenas nascem no Brasil sob o signo da tutela.

Uma vez aferido o status (isolado, em vias de integração ou integrado) dos indígenas, suas possibilidades de sobrevivência e acesso a direitos e políticas dependerá do lugar onde se vive, se dentro ou fora de uma área administrada pelo Estado que seja também definida como indígena. A isto podemos chamar não de cidadania, mas de "estadania", condição que torna o indígena sujeito de direitos apenas quando situado em uma unidade territorial gestada e gerida pelo Estado como "tradicionalmente indígena", em conformidade com as definições prescritivas de "ser índio" reguladas pelo Estado.

Portanto, para existir como indígena, hoje, não basta ser indígena, é necessário também estar e se ajustar permanentemente aos termos e limites de áreas reservadas para sua proteção através de políticas e práticas tutelares que ora tutelam diretamente os indígenas, ora tutelam e regulam seus direitos. É deste modo, para citar Claude Raffestin (1993), que o território se constitui como uma "prisão original", o que tem efeitos diretos e, em diversos contextos, perversos sobre como os indígenas constroem suas identidades, reelaboram suas culturas e expressam sua indianidade para si mesmos e seus outros.

Sob esta perspectiva, a regulação do território tem se mostrado mais importante para a gestão das políticas de reconhecimento e não-reconhecimento dos indígenas do que a própria população indígena. Na verdade, esta tem sido reduzida a meros corpos, entendidos como suporte físico, para justificar a própria política territorial e não o contrário. Dito de outro modo, os indígenas são reconhecidos em função da gestão de territórios e recursos, quando o que deveria ocorrer era o reconhecimento de territórios e a destinação de recursos em função da presença dos indígenas.

É possível depreender disto um quadro de progressivo abandono imposto aos povos indígenas pelo Estado e sociedade nacional: $1^{\circ}$ ) os indígenas não são cidadãos porque não pertencem à sociedade nacional e por isso são vulneráveis e objetos de tutela; $2^{\circ}$ ) para protegê-los, precisam ser progressiva e harmoniosamente integrados, o que fará deles, oportunamente, cidadãos (pouco importa se de segunda classe); $3^{\circ}$ ) diante da integração, deve-se promover sua emancipação considerado o apagamento completo de suas "condições peculiares" (entenda-se "aculturação"). A alternativa criada a isto nos anos 80 do século passado foi promover o reconhecimento oficial da autodeterminação indígena, o que implica exigir dos indígenas a ostentação de sua diferença como pré-condição para ter direitos, com consequências óbvias sobre a exibição e regulação de seus corpos, culturas e identidades, engendrando apresentações hiperreais de sua indianidade (RAMOS, 1998).

Como se pode notar, o indigenismo tem criado becos jurídicos e políticos sem saída para os indígenas através da materialização de seus discursos e práticas em 
regimes de indianidade particulares. Se num primeiro regime, o biopoder tutelar culmina no abandono completo do tutelado quando este é considerado integrado, no regime multiculturalista, a biopolítica indigenista esbarra na marginalização étnica e racial que faz com que apenas os indígenas "aldeados", inscritos em territórios estabelecidos pelo Estado possam ser clientes de políticas específicas, mas não necessariamente bem geridas. Isto quando não passam a ser responsabilizados pela gestão destas mesmas políticas, porém com recursos cada vez mais escassos.

Daí a luta pelo direito à autodeterminação associado à recuperação das terras ancestrais ser uma das prioridades dos movimentos indígenas. Muitas vezes, o significado político dessa luta é reivindicado como o direito a ser diferente em território próprio, como alternativa a se tornar um subalterno. Trata-se de uma luta antitotalitária, sobretudo se compreendermos os regimes totalitários como formas extremas de regulação até a efetiva aniquilação da diversidade. Se esta é uma das pautas dos movimentos indígenas, isto se deve ao fato de que secularmente e cotidianamente os indígenas veem-se obrigados a conformarem-se à perspectiva de seus dominadores. A verem-se, vestirem-se e transfigurarem-se segundo as representações de indianidade inventadas pelos brancos.

Muitos capitularam a esta dominação desenvolvendo formas "infelizes de consciência", como o fenômeno já estudado por Roberto Cardoso de Oliveira e chamado de "caboclismo" (1981 [1964]), e que corresponderia ao sujeito indígena negador de sua própria cultura e identidade, disposto a ocupar os postos mais baixos da estrutura social etnicamente segmentada. Cabe ainda reconhecer ofenômeno inverso e que poderíamos chamar de "hiperindianismo", que corresponderia ao sujeito indígena afirmador de uma cultura e identidade indígena tal como idealizada e romantizada pela sociedade dominante. Justamente aquela acionada publicamente nas situações sociais de conflito envolvendo o Santuário dos Pajés. Entre os dois fenômenos ideológicos, temos o indígena real, de carne e osso, obrigado a enfrentar ambas as formas de caricaturização ou clichagem de seus modos de expressão. Os regimes de indianidade inserem-se efetivamente em seus corpos e subjetividades, como a máquina de tortura outrora descrita por Kafka em seu conto "A colônia penal".

Portanto, tem sido em decorrência de políticas extremamente contraditórias da biopolítica indigenista que se dão as lutas indígenas por seus territórios enquanto espaços de autonomia para que conduzam as transformações de suas culturas, instituições e modos de ser nos seus próprios termos, buscando alternativas de re-existência como indígenas diante de uma dominação interétnica total sobre suas formas de vida e destinos coletivos. As lutas territoriais indígenas hoje visam superar os regimes e regulações das reservas e parques do passado para tornar, eles dizem "retomar", estes espaços como lugares de autonomia e liberdade.

Diante da crescente realidade dos indígenas em contextos urbanos e as novas formas de alteridade que aí se constroem, devemos aprender a desconstruir o modo como a "questão indígena" foi inventada como um problema de "integração" para desabilitar as formas de classificação que esse falso problema e seus dilemas 
criam para os indígenas e assim ajudar a abrir espaço, literalmente, para eles reassumirem o controle dos processos de representação de suas próprias identidades.

Penso que se voltarmos a pensar junto com os indígenas, em termos colaborativos e co-teorizadores, sobre como eles têm resistido aos regimes de indianidade e à violência das classificações indigenistas sobre suas identidades e corpos particulares poderemos também nos conscientizar e libertar dos regimes de modernidade mais disseminados, como são os regimes de racialidade, sexualidade e lucratividade que nos submetem, a todos, às formas de classificação que tem servido apenas à nossa redução enquanto seres humanos, cerceando nossa dignidade e liberdade existencial em sua pluralidade de expressões.

Acho que é para isso, dentre outras coisas, que devem servir nossas pesquisas sobre o Brasil plural, para enfrentar a construção oficial de um cotidiano absurdo e opressor através da ativação das diferenças que nos são constitutivas e que são alternativas a este estado imaginário de coisas. Talvez assim, consigamos produzir teorias que nos motivem a melhorar nossas práticas e a assumir novas e urgentes preocupações, a fazer novas alianças e relações que se fortaleçam a partir do horizonte comum de uma vida mais democraticamente plural e humanamente diversa. 


\section{Referências}

AGAMBEN, Giorgio. Homo Sacer: o poder soberano e a vida nua I. Trad. de Henrique Burigo. $1^{\text {a }}$ reimpressão. Belo Horizonte: Editora da UFMG, 2004 [1995].

BEZERRA, Marcos Otavio. Resenha: Um grande cerco de paz. Poder tutelar, indianidade e formação do estado no Brasil, de Antonio Carlos de Souza Lima. Mana, Rio de Janeiro, v. 3, n. 1, p. 195-197, abr. 1997.

BONFIL BATALLA, Guillermo. México profundo: una civilización negada. Cidade do México: Debolsillo, 2006.

CARDOSO DE OLIVEIRA, Roberto. O índio e o mundo dos brancos. 3. ed. Brasília: Editora da UnB; São Paulo: Pioneira, 1981 [1964].

CARMICHAEL, Stokely; HAMILTON, Charles V. Black power. London: Jonathan Cape, 1967.

CODEPLAN. População indígena: um primeiro olhar sobre o fenômeno do índio urbano na área metropolitana de Brasília. Brasília: SEPLAG/GDF, 2015.

CREVELS, Christian Ferreira. A semente pesada nas terras da discórdia: o Santuário dos Pajés e o signo imóvel. Interethnic@-Revista de estudos em relações interétnicas, v. 20, n. 3, nov.-dez., 2017.

FOUCAULT, Michel. Microfísica do poder. Trad. de Roberto Machado. Rio de Janeiro: Graal, 1995 [1979].

MENEZES, Gustavo Hamilton de Sousa. Sobre o direito consuetudinário dos povos indígenas e a transposição de barreiras em busca do reconhecimento estatal. In: GARCÉS, Claudia Leonor López; TEÓFILO DA SILVA, Cristhian; MORALES, Elena Nava (Orgs.). Desafiando leviatãs: experiências indígenas com o desenvolvimento, o reconhecimento e os Estados. Belém: Museu Goeldi, 2019. p. 169-181.

MILLER, Bruce Granville. Invisible indigenes: the politics of nonrecognition. Lincoln: University of Nebraska Press, 2003.

RAFFESTIN, Claude. Por uma geografia do poder. São Paulo: Ática, 1993.

TAIAIAKE ALFRED, Gerald. Colonialism and state dependency. Journal de la Santé Autochtone, nov. 2009.

TEÓFILO DA SILVA, Cristhian. Borges, Belino e Bento: a fala ritual entre os tapuios de Goiás. São Paulo: Annablume, 2002.

TEÓFILO DA SILVA, Cristhian. Cativando Maíra: a sobrevivência avá-canoeiro no Alto Rio Tocantins. Goiânia: PUC-GO; São Paulo: Annablume, 2010.

WILLIAMS, Jenny. Redefining institutional racism. Ethnic and Racial Studies, v. 8, n. 3, p. 323-348, 1985. 